\title{
Correction to: CD140b (PDGFR $\beta$ ) Signaling in Adipose-Derived Stem Cells Mediates Angiogenic Behavior of Retinal Endothelial Cells
}

\author{
Ramesh Periasamy ${ }^{1}$ - Sally L. Elshaer ${ }^{1,2}$ - Rajashekhar Gangaraju ${ }^{1,3}$
}

Published online: 24 February 2020

(C) The Regenerative Engineering Society 2020

Correction to: Regenerative Engineering and Translational Medicine (2019) 5:1-9 https://doi.org/10.1007/s40883-018-0068-9

An affiliation for Dr. Sally L. Elshaer was inadvertently omitted from this paper:

Department of Pharmacology and Toxicology, College of Pharmacy, Mansoura University, 60 Elgomhoria St, Mansoura, 35516, Egypt

Publisher's Note Springer Nature remains neutral with regard to jurisdictional claims in published maps and institutional affiliations.

The online version of the original article can be found at https://doi.org/ 10.1007/s40883-018-0068-9

Rajashekhar Gangaraju

sgangara@uthsc.edu; https://academic.uthsc.edu/faculty/

328026.html

1 Department of Ophthalmology, Hamilton Eye Institute, University of Tennessee Health Sciences Center, 930 Madison Ave, Suite 768, Memphis, TN 38163, USA

2 Department of Pharmacology and Toxicology, College of Pharmacy, Mansoura University, 60 Elgomhoria St, Mansoura 35516, Egypt

3 Department of Anatomy and Neurobiology, University of Tennessee Health Sciences Center, 930 Madison Ave, Suite 768, Memphis, TN 38163, USA 